\title{
Pyrolysis - Field Ionization Mass Spectrometry - A New Method for Direct, Rapid Characterization of Tobacco*
}

\author{
by $H .-R$. Schulten
}

Department of Trace Analysis, Facbhochschule Fresenius, Wiesbaden, Federal Republic of Germany

\section{SUMMARY}

For the first time, pyrolysis - field ionization (Py-FI) mass spectra of the tobacco blends of three different cigarette brands have been recorded in the mass range up to 1000 mass units and evaluated by operational fingerprinting techniques. Due to the high reproducibility of the applied methods, all three tobacco blends could be differentiated clearly with several univariate or multivariate statistical methods. Feature scaling with Fisher ratios revealed that the signal at $m / z 93$, mainly due to aniline, is the most suited to distinguishing the tobacco blends analysed. Principal component analysis showed the variety of pyrolytic reactions during the thermal decomposition of tobacco in high vacuum. It revealed that, in addition to aniline, lignin-related signals can also be used for a clear differentiation. From the whole pattern of Py-FI mass spectrum, nearestneighbour relationships are visualized by the non-linear mapping technique and further classification of tobacco blends is obtained by hierarchical cluster analysis. A thorough chemical interpretation of the data obtained should give new insights into the structure of tobacco and its pyrolytic decomposition. Pyrolysis - soft ionization mass spectrometry in combination with pattern recognition techniques appears to provide a useful tool for future investigations connected with the quality control of commercial tobacco products.

\footnotetext{
* Presented, in part, at the 6th International Symposium on Analytical and Applied Pyrolysis, Wiesbaden, 1984.

Received: 17th March 1986 - accepted: 30th October 1986.
}

\section{ZUSAMMENFASSUNG}

Zum exsten Mal wurden nach Pyrolyse-Feldionisation (Py-FI) Massenspektren von Tabakmischungen dreier verschiedener Zigarettensorten in dem Bereich von bis zu 1000 Masseneinheiten aufgenommen und mit Mustererkennungstechniken ausgewertet. Aufgrund der hohen Reproduzierbarkeit der angewandten Methoden konnten alle drei Tabakmischungen mit Hilfe von uni- oder multivariaten statistischen Methoden deutlich unterschieden werden. Merkmalerkennung aufgrund von Fisher-Quotienten zeigte, daß das Signal bei $m / z$ 93, vorwiegend Anilin zugeordnet, am besten geeignet ist, die analysierten Tabakmischungen $z u$ unterscheiden. Die Hauptkomponentenanalyse verdeutlichte die Vielzahl pyrolytischer Reaktionen wăhrend des thermischen Abbaus von Tabak im Hochvakuum. Sie zeigte, daß neben Anilin auch durch Lignin bedingte Signale für eine deutliche Trennung verwendet werden können. Unter Verwendung des ganzen Musters von Py-FI-Massenspektren und nichtlinearer Projektion konnten Âhnlichkeiten dargestellt werden. Eine weitere Klassifizierung erfolgte durch eine hierarchische Cluster-Analyse. Eine gründliche chemische Interpretation der erhaltenen Daten kann neue Einblicke in die Struktur und die pyrolytische Zersetzung von Tabak geben. Pyrolyse und Massenspektrometrie mit schonenden Ionisierungsverfahren in Verbindung mit Mustererkennungstechniken scheinen eine nützliche Methode für zukūnftige Untersuchungen zur Qualitãtskontrolle kommerzieller Tabakprodukte zu sein. 


\section{RESUME}

Des mélanges de tabac correspondant à trois variétés différentes de cigarettes ont été étudiés pour la première fois par combinaison de pyrolyse (Py), ionisation dans un champ ionisant (FI) et spectrométrie de masse dans un domaine allant jusqu'à 1000 unités de masse puis analysés au moyen de techniques d'identification (pattern recognition). Etant donné la haute reproductibilité de la méthode employée, les trois mélanges de tabac ont pu être nettement distingués les uns des autres en recourant à des méthodes statistiques à une ou plusieurs variables. L'utilisation des quotients de Fisher a montré que le signal $\mathrm{m} / \mathrm{z} 93$, essentiellement dû à l'aniline, était celui qui convenait le mieux pour différencier les mélanges de tabac examinés. L'analyse des composants principaux a fait ressortir le grand nombre de réactions pyrolytiques qui se produisent pendant la décomposition thermique du tabac sous un vide poussé. Elle a montré, qu'outre l'aniline, on pouvait aussi utiliser les signaux dus à la lignine pour différencier nettement les tabacs. Des ressemblances ont pu être mises en évidence grâce à l'utilisation de l'ensemble des spectres de masse sous Py-FI combinée à une projection non linéaire. Une autre classification a été effectuée au moyen d'une analyse arborescente hiérarchisée (cluster). L'interprétation chimique fondamentale des résultats obtenus peut fournir un nouvel aperçu de la structure et de la décomposition pyrolytique du tabac. Associée aux techniques d'identification, la spectrométrie de masse après pyrolyse et ionisation douce, apparait ainsi comme une méthode pouvant s'avérer à l'avenir d'une grande utilité pour les examens effectués en vue du contrôle de qualité des produits de tabac du commerce.

\section{INTRODUCTION}

Tobacco is a very complex biomatrix which has been extensively analysed with a wide variety of techniques. Many thousands of substances have been identified in tobacco and tobacco smoke $(1,2)$. In addition to conventional procedures, analytical pyrolysis (Py) techniques have now been developed which are appropriate for the investigation of volatile substances derived from biomaterials by direct transfer and/or thermal decomposition. In combination with mass spectrometry (MS) and computerized multivariate data evaluation, Py MS offers a promising approach to the analysis of extremely complex organic materials (3).

Although pyrolytic processes occur in tobacco during smoking (4), there is, to the best of our knowledge, only one study which deals with the direct (in-source) Py MS and Py GC MS of tobacco (5).

High-vacuum pyrolysis processes of biomass appear, at least at relatively low temperatures, to be dominated by straightforward thermal decomposition reactions with little or no intermolecular reactions (6). By using soft ionization modes such as field ionization (FI), the mass spectrometric fragmentation of the generated chemical species is minimal (7) and the spectra are governed by intense molecular ions of primary building blocks. Therefore, Py-FI MS seems to be very suitable for facilitating the rapid characterization of different tobaccos or tobacco blends.

Due to their high reproducibility, the Py-FI mass spectra can be used as characteristic fingerprints and processed by pattern recognition techniques (8). The chemical applications of fingerprinting techniques involve classification and identification of original material from library or reference fingerprints. Generally, little or no chemical interpretation of the pattern is attempted or even required. Computer evaluation of pyrolysis fingerprints which can be obtained quickly with modern Py-FI MS opens up important new areas of application, namely screening, quality control, and process monitoring.

For the first time, the combination of Py-FI MS and pattern recognition techniques is being applied to tobacco. The aim of this pilot study is to examine whether the tobacco blends of three different commercial cigarettes can be distinguished by Py-FI MS. Furthermore, it was of interest to determine which characteristic key features could be found that are responsible for a significant differentiation of various tobacco materials. Identification of highly significant pyrolysis products is reported, and the results suggest that structure/pyrolyzate relationships can be established.

\section{MATERIALS AND METHODS}

The general experimental procedure for the investigation of tobacco products is described in Figure 1. As shown in this block diagram, the starting material, which can be anything from a raw tobacco to the com-

\section{Figure 1.}

Scheme of the methodology using mass spectrometry with in-source pyrolysis and soft lonization in combination with chemometric techniques such as Fisher weighting, principal component and cluster analyses.

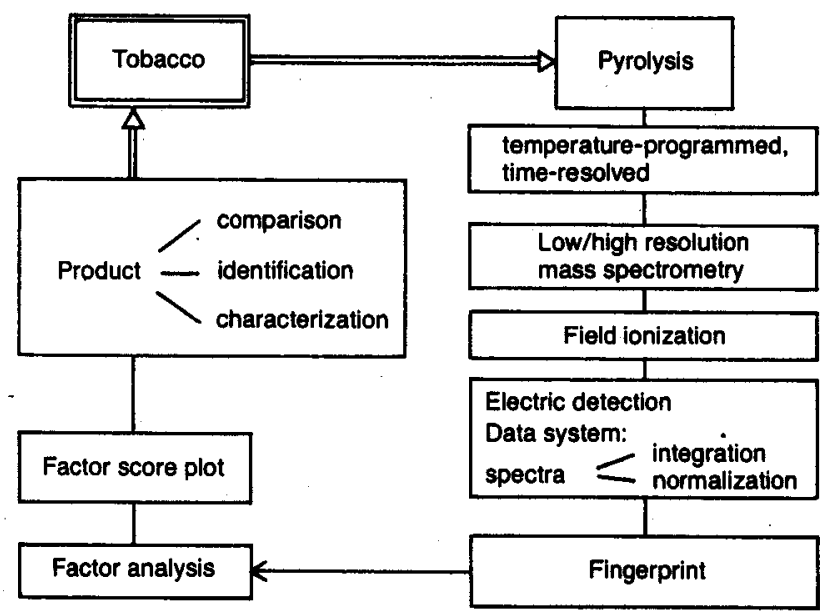


mercial finished product, is pyrolyzed in a temperatureprogrammed step in the high vacuum of the mass spectrometer under low mass resolution conditions. Field ionization is utilized as a soft ionization technique in order to reduce mass spectrometric fragmentation and avoid the overlapping of such fragment ions with the primarily formed thermal degradation products which appear in the spectra as intact molecular ions. In view of the complexity of the pyrolyzate mixtures obtained from biomaterials, this is one of the essential features of this methodology. Following the integration and normalization of the electrically-recorded mass spectra, characteristic fingerprints can be obtained. Differentiation of tobacco samples by operational fingerprinting is the aim at this stage of the investigation. To compare tobacco (and smoke) properties factor analysis follows and allows the identification and chemical characterization of the tobacco product, thus closing the analytical circle illustrated in Figure 1.

\section{Tobacco Samples}

Three commercially available, well-known cigarette brands were purchased, their wrappers removed and the tobacco blends investigated. According to the data on the different cigarette packages the nicotine concentration varied from 0.4 to $0.7 \mathrm{mg} /$ cigarette and the condensate concentration from 9 to $15 \mathrm{mg} /$ cigarette (according to DIN 10240, with permitted product scatter as defined in DIN 10246). Certain selected mean smoke properties of the three cigarette brands were determined and are given in Table 1.

\section{Table 1.}

Selected mean smoke properties of the cigarette brands investigated.*

\begin{tabular}{c|c|c|c}
\hline Tobacco & $\begin{array}{c}\text { Nicotine } \\
\text { (mg/cig.) }\end{array}$ & $\begin{array}{c}\text { Condensate (dry) } \\
\text { (mg/cigarette) }\end{array}$ & $\begin{array}{c}\text { Carbon monoxide } \\
\text { (ml/cigarette) }\end{array}$ \\
\hline 1 & 0.424 & 8.88 & 9.2 \\
2 & 0.500 & 10.30 & 9.3 \\
3 & 0.759 & 13.82 & 10.8 \\
\hline
\end{tabular}

" according to DIN 10240

\section{Instrumental}

For Py-FI MS, about $200 \mu \mathrm{g}$ of dried and powdered tobacco were placed in an aluminium crucible in the direct introduction system of the mass spectrometer (Figure 2). The double-focusing instrument (Finnigan MAT 731 (Bremen, Federal Republic of Germany)) equipped with the combined $\mathrm{EI}^{*} / \mathrm{FI} / \mathrm{FD}^{* *}$ ion source was used at medium mass resolution. For compound identification high mass resolution and Curie-point Py GC MS (5) were employed. The samples were heated linearly from $50^{\circ} \mathrm{C}$ to $350^{\circ} \mathrm{C}$ at a rate of $0.4^{\circ} \mathrm{s}^{-1}$. In general, about thirty spectra at a mass range of between

\footnotetext{
* electron ionization * field desorption
}

Figure 2.

Schematic display of in-source pyrolysis using the commerclally avallable direct introduction system. Field ionization is utilized as soft ionization mode.

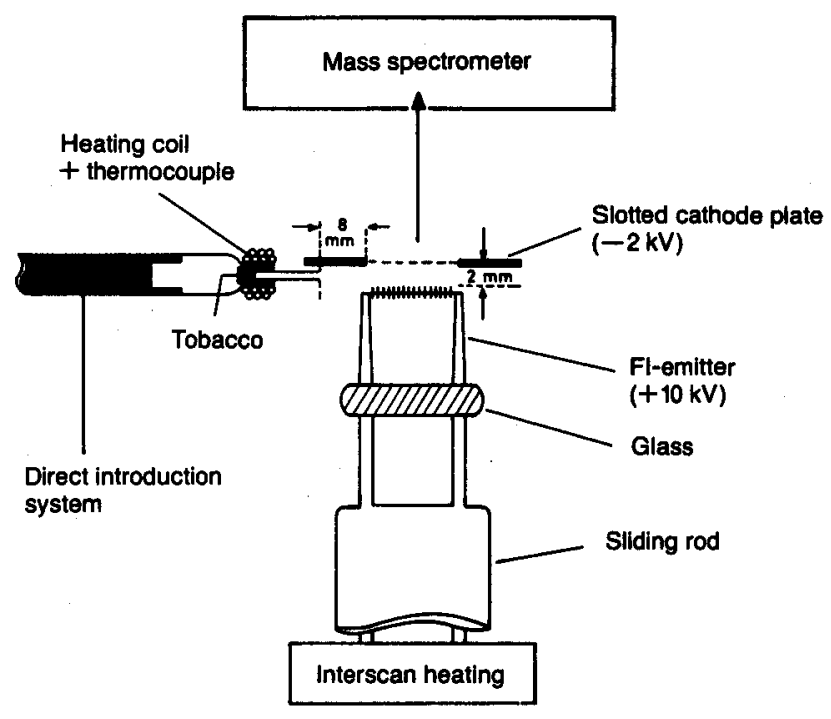

$m / z \quad 30$ and $m / z \quad 1,000$ were registered electrically during this temperature interval. The FI signals of each magnetic scan were integrated and plotted with the SS 200 data system (Finnigan MAT) to give a summed spectrum. To achieve the desired good reproducibility, three separate runs of each specimen were recorded and averaged to give a survey spectrum as shown in Figure 3. This procedure was repeated ten times for each sample to enable statistical evaluation to be made.

It is important to note that the time taken to produce a survey spectrum is less than one hour. Any magnetic or quadrupole instrument can be employed in this manner for the novel method of tobacco analysis as introduced in the present work.

\section{Data Evaluation}

The thirty averaged spectra of the three different tobacco blends were processed statistically using the ARTHUR program (9). After normalizing the spectra to their total ion counts, 230 features between $\mathrm{m} / \mathrm{z} 51$ and $m / z 490$ were used for further calculation. A Euclidean distance matrix of the spectra set was calculated in order to identify nearest-neighbour sequences. The distance matrix was visualized by applying the non-linear mapping technique. This subroutine program calculates two-dimensional coordinates of all samples iteratively, preserving as much as possible the distances between each sample. The ions which exhibit the most characteristic features for differentiating the various groups of tobaccos were found by calculating the Fisher ratio. The ions with the highest ratios show high inter-sample deviation and low intra-sample deviation. Thus, they are the most suitable for distinguishing the three com- 
Table 2.

Unrotated matrix of the first five principal components extracted, showing loadings of signals selected from pyrolysis - field ionization mass spectra of tobacco."

\begin{tabular}{|c|c|c|c|c|c|c|}
\hline & & \multicolumn{5}{|c|}{ Principal components } \\
\hline & & 1 & $\|$ & III & IV & v \\
\hline & & \multicolumn{5}{|c|}{ Variance $[\Sigma$ 84.9\%] } \\
\hline & & $63.3 \%$ & $10.5 \%$ & $4.4 \%$ & $3.4 \%$ & $3.3 \%$ \\
\hline Fisher weight & $m / z$ & \multicolumn{5}{|c|}{ Loadings } \\
\hline 20.0 & 93 & 0.16 & 0.11 & 0.14 & -0.03 & 0.00 \\
\hline 10.2 & 110 & -0.11 & -0.30 & 0.01 & -0.15 & 0.08 \\
\hline 5.5 & 144 & -0.16 & -0.03 & -0.09 & 0.20 & 0.06 \\
\hline 4.0 & 126 & -0.15 & -0.09 & -0.14 & 0.17 & -0.06 \\
\hline 3.3 & 124 & -0.09 & -0.24 & -0.02 & 0.27 & -0.34 \\
\hline 2.5 & 410 & 0.15 & -0.08 & 0.05 & 0.18 & 0.22 \\
\hline 2.0 & 156 & 0.12 & 0.03 & -0.39 & 0.05 & 0.02 \\
\hline
\end{tabular}

" Loadings $\geq 10.21$ are given in bold print.

mercial tobacco blends. The 50 standardized signals with the highest Fisher ratio were used to perform a principal component analysis and a hierarchical cluster analysis. By using the standardized data, a few new, orthogonal vectors (principal components) are extracted, maintaining the whole variance of the original data set. The correlation coefficients between the original features and the artificial principal components are called loadings and are shown in Table 2 for certain selected features and principal components. Now each sample can be described from only a few principal components instead of numerous original signals which can be intercorrelated and then contain the same information. The discriminant power of the principal components is shown in Figure 5 by plotting the scores of the first principal component versus the scores of the second principal component. Finally, by use of the original standardized data set, all samples are clustered into groups on the basis of their similarity in size and variation. The values of the similarity index calculated in the hierarchical cluster analysis are plotted as contour lines in the two-dimensional linear map and act as an additional discriminant dimension.

\section{RESULTS AND DISCUSSION}

\section{Field-Ionization Mass Spectrum of Tobacco}

A typical Py-FI mass spectrum of tobacco in the mass range from $m / z$ to $m / z 1,000$ is shown in Figure 3 . Recently, a similar spectrum in the mass range from $\mathrm{m} / \mathrm{z} 50$ to $\mathrm{m} / \mathrm{z} 500$ and its corresponding thermogram were discussed and some signals of molecular ions identified by Py GC EI/FI MS (5). As reported for Py-
FI mass spectra of coal (8), all spectra of tobacco, upon visual inspection, look very similar and no clear, reliable differentiation between the various types of tobacco blend is possible.

The series of ions at $m / z 96,98,114,126$ and 144 is partly due to hexosyl subunits derived from cellulose (7). The signal of the ion $m / z 162$ is caused primarily by nicotine (5). However, levoglucosan (7) can also contribute to the relative abundance of this signal. In addition to cellulose, the signals related to lignin, another non-extractable portion of tobacco, are seen at $\mathrm{m} / \mathrm{z} 124,138,150,152$ and 164 . These signals are related to guaiacyl units gradually substituted by a propenoid side-chain (10). Recent studies on the pyrolysis of tobacco suggest that the non-extractable skeletons of cellulose, hemicellulose and lignin serve as specific precursors for volatile carbonyl compounds (11). HALKET and SCHULTEN (5) have tentatively identified acetic acid $(m / z 60)$, phenol $(m / z 94)$, two dimethylfurans $(m / z 96)$, 2-furanmethanol $(m / z 98)$, pyrocatechol and 5-methyl-2-furancarboxaldehyde $(m / z 110)$, acetylcyclopentane $(m / z 112), 2$-methoxyphenol $(m / z 124)$ and 2 -hydroxy-4-methylacetophenone $(m / z 150)$.

Fragment ions or molecular ions of gases (12) are seen at $m / z 31\left(\mathrm{CH}_{3} \mathrm{O}^{+}\right), m / z 43\left(\mathrm{C}_{3} \mathrm{H}_{7}^{+}, \mathrm{C}_{2} \mathrm{H}_{3} \mathrm{O}^{+}\right), m / z 44$ $\left(\mathrm{CO}_{2}^{+}, \mathrm{C}_{2} \mathrm{H}_{4} \mathrm{O}^{+}\right), m / z \quad 45\left(\mathrm{C}_{2} \mathrm{H}_{5} \mathrm{O}^{+}\right)$and $\mathrm{m} / \mathrm{z} 58$ $\left(\mathrm{C}_{3} \mathrm{H}_{6} \mathrm{O}^{+}\right)$. The most frequently used humectants for tobacco are 1,2-propanediol and glycerol (1). The signals of their water-eliminated products are seen at $m / z 58$ and $m / z$ 74. The signal at $m / z \quad 69$ is caused either by a nitrogen-containing fragment or by an aliphatic, unsaturated fragment (in addition to the $\mathrm{CF}_{3}{ }^{+}$ ion of the reference compound perfluorokerosene).

Other higher-mass molecular ions were previously identified (5) as aniline $(m / z \quad 93)$, dimethylaniline 
Figure 3.

Fleld lonization mass spectra of a typical tobacco sample (the base peak corresponds

to approximately 200,000 counts).

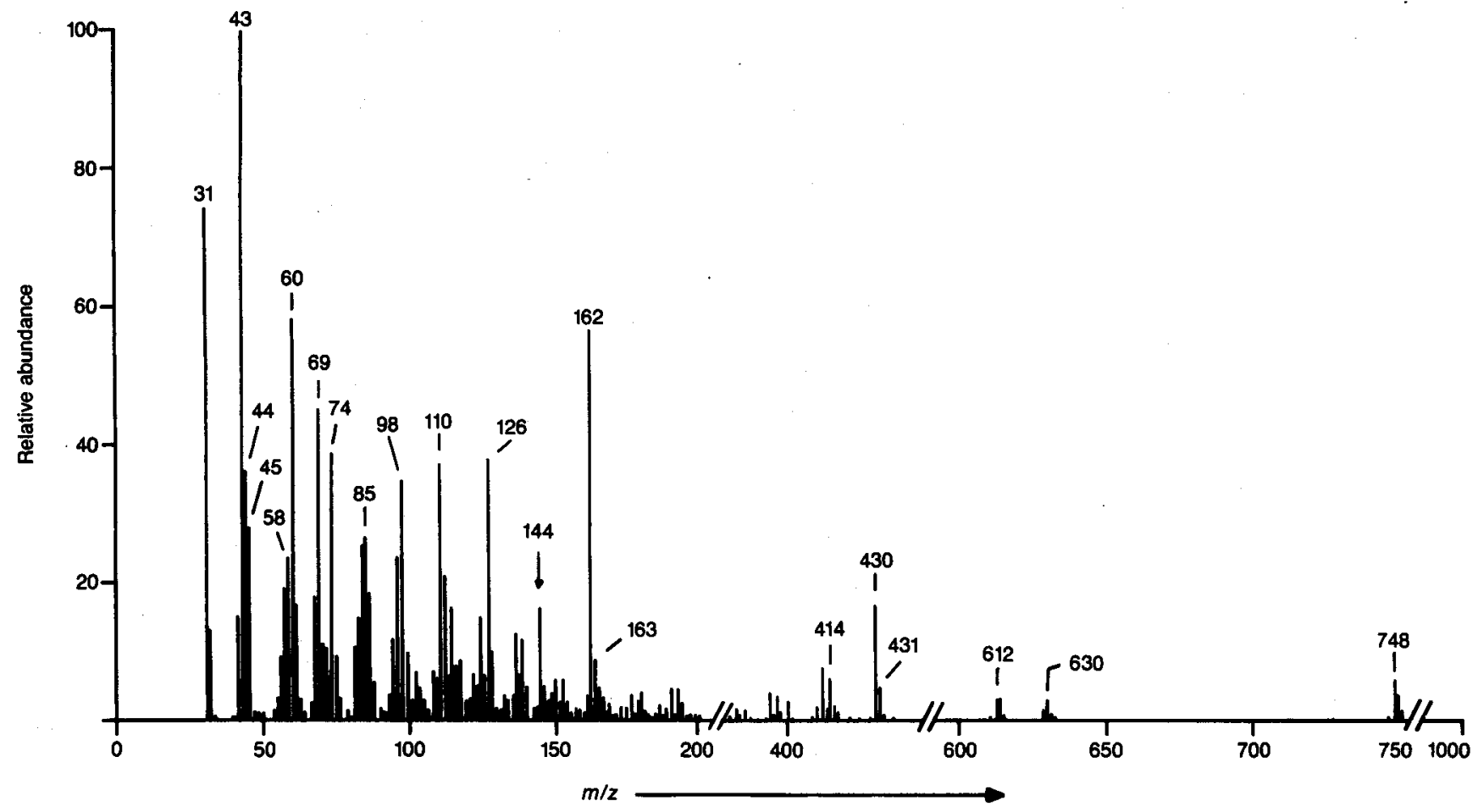

$(m / z 121)$, limonene $(m / z 136)$, linalool $(m / z 154)$, bipyridine $(m / z 156)$, isoeugenol $(m / z 164)$ neophytadiene $(\mathrm{m} / \mathrm{z} 278)$, squalene $(\mathrm{m} / \mathrm{z} 410)$ and $\alpha$-tocopherol $(\mathrm{m} / \mathrm{z} 430)$. All these substances have been found in tobacco or tobacco smoke (1). This confirms that a Py-FI mass spectrum gives a good insight into the complex structure of tobacco.

On the basis of data from literature, we put forward additional compounds which can be seen in the Py-FI mass spectrum of tobacco in Figure 3. The molecular ions of the commonest free phytosterols of tobacco give signals for campesterol at $\mathrm{m} / \mathrm{z} 400$, stigmasterol at $m / z 412$ and sitosterol at $m / z 414$ (13). Furthermore, molecular ions of solanesol at $\mathrm{m} / \mathrm{z} 630$ and solanesenes at $m / z 612$ can be seen. These isoprenoids appear to be quantitatively the highest free terpenoids of tobacco (1). The high mass signal at $m / z 748$ can be explained by a wax ester of tobacco which is composed of a solanesol, stigmasterol or sitosterol unit esterified with saturated or unsaturated $n$-fatty acids (1). Previously it was shown that molecular ions of high molecular weight wax constituents can be detected by FI MS (14).

\section{Univariate Statistical Evaluation}

For the following considerations, the Fisher ratios of each feature used were calculated and are shown in Table 2 for selected signals. The standardized ion intensities of the two ions with the highest Fisher weight are plotted in Figure 4. The ion at $\mathrm{m} / \mathrm{z} 93$ is due solely to aniline (5), a pyrolytic product of the thermal decomposition of nitrogen-containing substances. Aniline is

\section{Figure 4.}

Scatter plot of standardized ion Intensities at $m / 293$ versus $\mathrm{m} / 2110$ for Tobaccos 1, 2 and 3 .

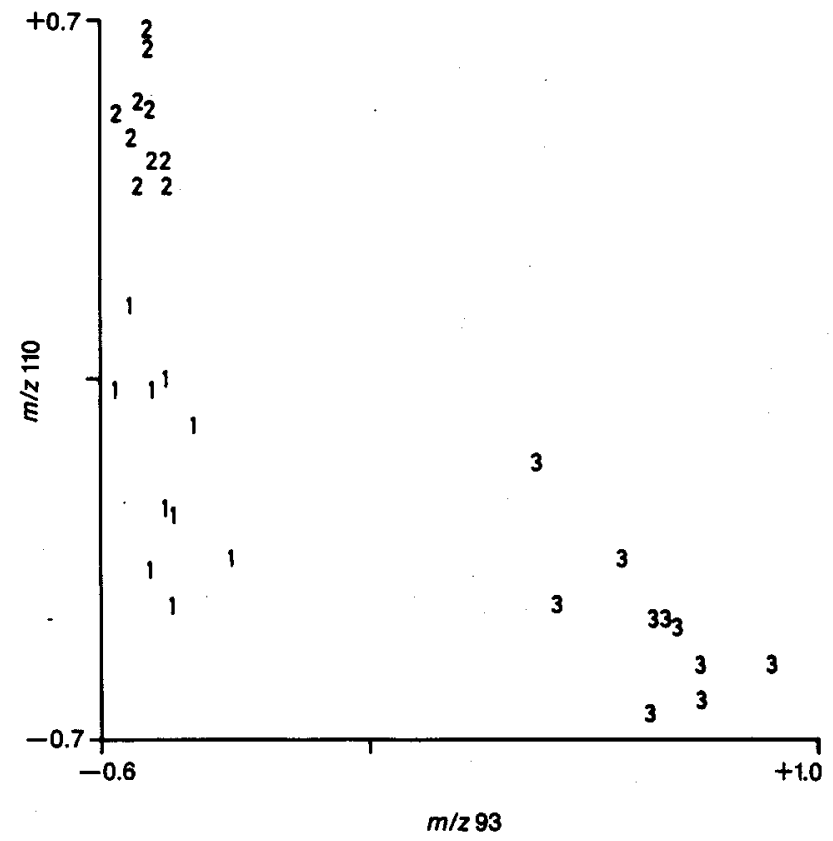


primarily found in the sidestream smoke of a smouldering cigarette (15). The signal at $m / z 110$ is primarily due to pyrocatechol and 5-methyl-2-furancarboxaldehyde. Both are pyrolytic products of polysaccharides (cellulose) and polyphenols (lignin). From these two signals alone, a significant differentiation of the three blends of tobacco investigated is possible. It is surprising that the highest discriminant power, expressed by the highest Fisher ratio, is due to aniline (Table 2), the molecular ion of which causes only relative abundances between 0 and $5 \%$ whilst the signals at $\mathrm{m} / \mathrm{z} 110$ vary from $21 \%$ to $27 \%$. Considering the standardized abundances of the two signals the internal variation between the ten measurements of Tobacco 2 is very low compared to the scattering of samples of Tobacco 1 and Tobacco 3 (Figure 4). However, the reproducibility of all measurements is good enough to differentiate the three blends. Basically, Tobacco 3 is distinguished from the other blends by its aniline signal, i.e. it appears to contain a certain tobacco or additive which preferentially produces aniline during pyrolysis. Tobacco 1 and Tobacco 2 are only differentiated by the relative abundance of their signals at $m / z 110$, indicating different contents of lignin or cellulose.

\section{Multivariate Statistical Evaluation}

To give more insight into the structure of Py-FI mass spectra of tobacco, a principal component analysis was performed. Certain selected features and principal components are shown in Table 2. The first five principal components extracted describe the whole data set of 50 features with $85 \%$ of its variance. In contrast to the signals at $\mathrm{m} / \mathbf{z} 110$, surprisingly, the signals at $\mathrm{m} / \mathrm{z} 93$ do not significantly load any of the 29 principal components extracted. Therefore no single, defined process or other substances can be related to the production of aniline.

The variety of pyrolysis reactions is expressed by the first principal component ( $\mathrm{I}$ in Table 2) which is not dominated by any of the 50 signals used, although it represents $63.3 \%$ of the total variance. The second principal component (II) represents the pyrolysis of lignin and is mainly loaded by signals at $\mathrm{m} / \mathrm{z} 110$ and $m / z 124$. The third principal component (III) probably represents pyrolytic processes which produce units of pyridine or bipyridine at $\mathrm{m} / \mathrm{z} 79$ and 156 respectively. The production of these aromatic nitrogen compounds occurs during the pyrolysis of glycine and nicotine (15, 16). However, it seems that aniline is only involved to a minor extent in these decomposition reactions. The fourth principal component (IV) represents the thermal decomposition of cellulose with its pyrolytic products at $m / z \quad 144$ and $m / z 126$. The signal at $m / z 124$ seems to be caused by at least three pyrolytic processes because this feature shows high loadings in three principal components including the fifth principal component (V) which is dominated by molecular ions of high molecular weight compounds such as squalene at $\mathrm{m} / \mathrm{z} 410$.
Figure 5.

Score plot of the first princlpal component (variance 63.3\%) versus the second princlpal component (variance 10.5\%) of Tobaccos 1, 2 and 3.

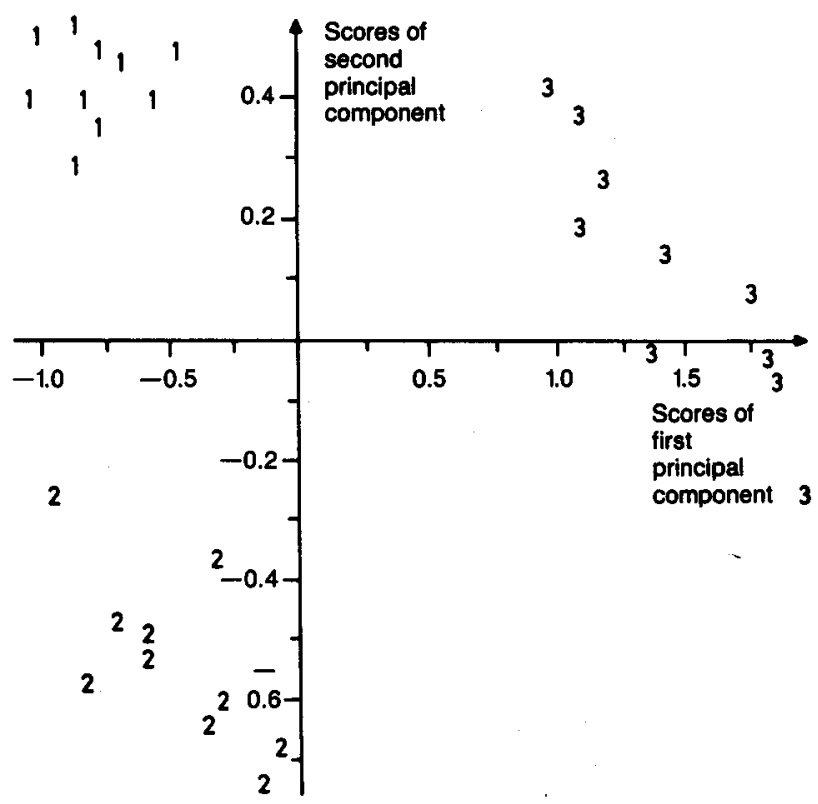

This brief interpretation of a very reduced loading matrix results in a thorough description of the most relevant processes which can occur during tobacco pyrolysis. The orthogonality of the principal components extracted indicates that the thermal decomposition of polyphenols occurs independent of the thermal decomposition of polysaccharides and/or the sublimation of non-polymeric constituents. Therefore a rigorous chemical interpretation of the whole loading matrix can provide new insight into unknown pyrolytic processes and interactions between features detected during $\mathrm{Py}$ FI MS.

Apart from elucidating chemical structure or thermal decomposition reactions, principal components can also be used as artificial variables in order to differentiate various blends of tobacco. In Figure 5, the scores of the first principal component versus the second principal component are plotted for each measurement. Both principal components describe $73.8 \%$ of the total variance of the whole data set. Again, a clear differentiation is possible. The second principal component is dominated by signals derived from lignin. This axis is comparable to the $m / z 110$ axis in Figure 4. The feature . $m / z 110$ is negatively correlated to the second principal component (Table 2). Thus the interpretation of the scatter plot in Figure 4 and the principal-component score plot in Figure 5 reveals that Tobacco 3 produces fewer signals related to lignin than do the other two blends. Both plots also show that Tobacco 2 produces the most abundant lignin-related signals during its pyrolysis. This finding indicates that the lignin content of commercially available cigarettes is one of the charac- 
teristic features which are suitable for making a significant differentiation. Unfortunately, the first principalcomponent axis in Figure 5 cannot be chemically interpreted because no features load this principal component significantly. However, the score plot shows clearly that at least two dimensions are necessary to distinguish different tobacco blends. Besides ligninderived components, aniline seems to be suitable for a clear differentiation (Figure 4). Aniline has been reported as a pyrolytic product of proteins and amino acids (16). However, no further chemical interpretation and quality assessment are possible at the present time.

From all 230 features, a Euclidean distance matrix was calculated and visualized as a two-dimensional non-linear map (Figure 6). Again, a clear separation is obtained between the three tobacco blends, indicating the discriminant power of the whole Py-FI pattern of tobacco. However, the single measurements are scattered to a larger extent, resulting in a reduced distance between the three blends. This example shows that differentiation can be improved by using fewer features selected by Fisher ratios or principal component analysis.

Obviously the discriminant power of the non-linear mapping technique can be improved by introducing a third dimension. Instead of projecting the distance matrix onto a three-dimensional space, a hierarchical cluster analysis was carried out and the similarity values (in $\%)$ were plotted as contour lines in the two-dimensional non-linear map (Figure 6). Now it becomes clear that Tobacco 3 must be very different from Tobaccos 1 and 2 which finally form one group. This finding corresponds very well with the basic smoke parameters listed in the experimental part. Tobacco 3 shows higher concentrations of nicotine, condensate and carbon monoxide compared to the values for Tobaccos 1 and 2. In addition, the difference between the measurements No. 13 (Tobacco 2) and No. 10 (Tobacco 1) can obviously be seen. Both measurements are integrated significantly into their groups. With the exception of the classification and description of nearest-neighbour sequences, this visualization technique gives no insight into chemical structures and differences. However, a valid statement can be made concerning the similarity of different tobacco blends. Furthermore, it seems that the results of pattern recognition can be correlated with external features such as smoke parameters, suggesting that the whole pattern of a Py-FI mass spectrum is suited to predict smoke properties.

\section{CONCLUSION}

These preliminary results of the combination of Py-FI MS and pattern recognition indicate that it is possible to differentiate tobacco blends of various commercially available cigarettes. The application of operational fingerprinting techniques does not merely lead to a classification of tobacco blends but also gives insight into the chemical structures of tobacco and its pyrolytic de- composition processes. If the analytical approach in correlating the mass spectrometric signals of tobacco blends with other physical and chemical features of cigarettes is successful (17), then the operational fingerprinting of Py-FI mass spectra will be a fast, reliable and inexpensive method in future quality control.

\section{REFERENCES}

1. Wynder, E. L., and D. Hoffmann: Tobacco and tobacco smoke - Studies in experimental carcinogenesis; Academic Press, New York and London, 1967.

2. Dube, M. F., and C. R. Green: Methods of collection of smoke for analytical purposes; Recent Adv. Tob. Sci. 8 (1982) 42-102 and references cited therein.

3. Meuzelaar, H. L. C., W. Windig, A. C. Harper, S. M. Huff, W. H. McClennen and J. M. Richards: Pyrolysis mass spectrometry of complex organic materials; Science (Wash., D.C.) 226 (1984) 268274.

4. Baker, R. R.: Product formation mechanisms inside a burning cigarette; Prog. Energy Combust. Sci. 7 (1981) 135-153.

5. Halket, J. M., and H.-R. Schulten: Rapid characterization of tobacco by combined direct pyrolysis - field ionization mass spectrometry and pyrolysis gas chromatography-mass spectrometry; J. Anal. Appl. Pyrolysis 8 (1985) 547-560.

6. Schulten, H.-R., K. E. Murray and N. Simmleit: Natural waxes investigated by soft ionization mass spectrometry; Z. Naturforsch. Teil C Biochem. Biophys. Biol. Virol. 32 (1987), in the press.

7. Schulten, H.-R.: Relevance of analytical pyrolysis studies to biomass conversion; J. Anal. Appl. Pyrolysis 6 (1984) 251-272.

8. Schulten, H.-R., N. Simmleit and R. Müller: Distinction of coals and their extracts by field ionization mass spectrometry and pattern recognition; Fresenius Z. Anal. Chem. 323 (1986) 450-454.

9. Harper, A. M., D. L. Duewer, B. R. Kowalski and J. L. Fasching: ARTHUR and experimental data analysis - The heuristic use of a polyalgorithm; ACS (Am. Chem. Soc.) Symp. Ser. 52 (1977) 14-51.

10. Haider, K., and H.-R. Schulten: Pyrolysis field ionization mass spectrometry of lignins, soil humic compounds and whole soil; J. Anal. Appl. Pyrolysis 8 (1985) 317-331.

11. Brunnemann, K. D., and D. Hoffmann: Pyrolytic origins of gas phase constituents of cigarette smoke; Recent Adv. Tob. Sci. 8(1982) 103-140.

12. Baker, R. R., and K. D. Kilburn: The distribution of gases within the combustion coal of a cigarette; Beitr. Tabakforsch. 7 (1973) 79-87.

13. Schmeltz, I., A. de Paolis and D. Hoffmann: Phytosterols in tobacco - Quantitative analysis and fate in tobacco combustion; Beitr. Tabakforsch. 8 (1975) 211-218. 
Figure 6.

Non-linear map (stress 3.8\%) of Tobacco 1 (samples 1-10), Tobacco 2 (samples 1120) and Tobacco 3 (samples $21-30$ ). The contour lines show similarity values of $40 \%, 50 \%, 60 \%$ and $80 \%$.

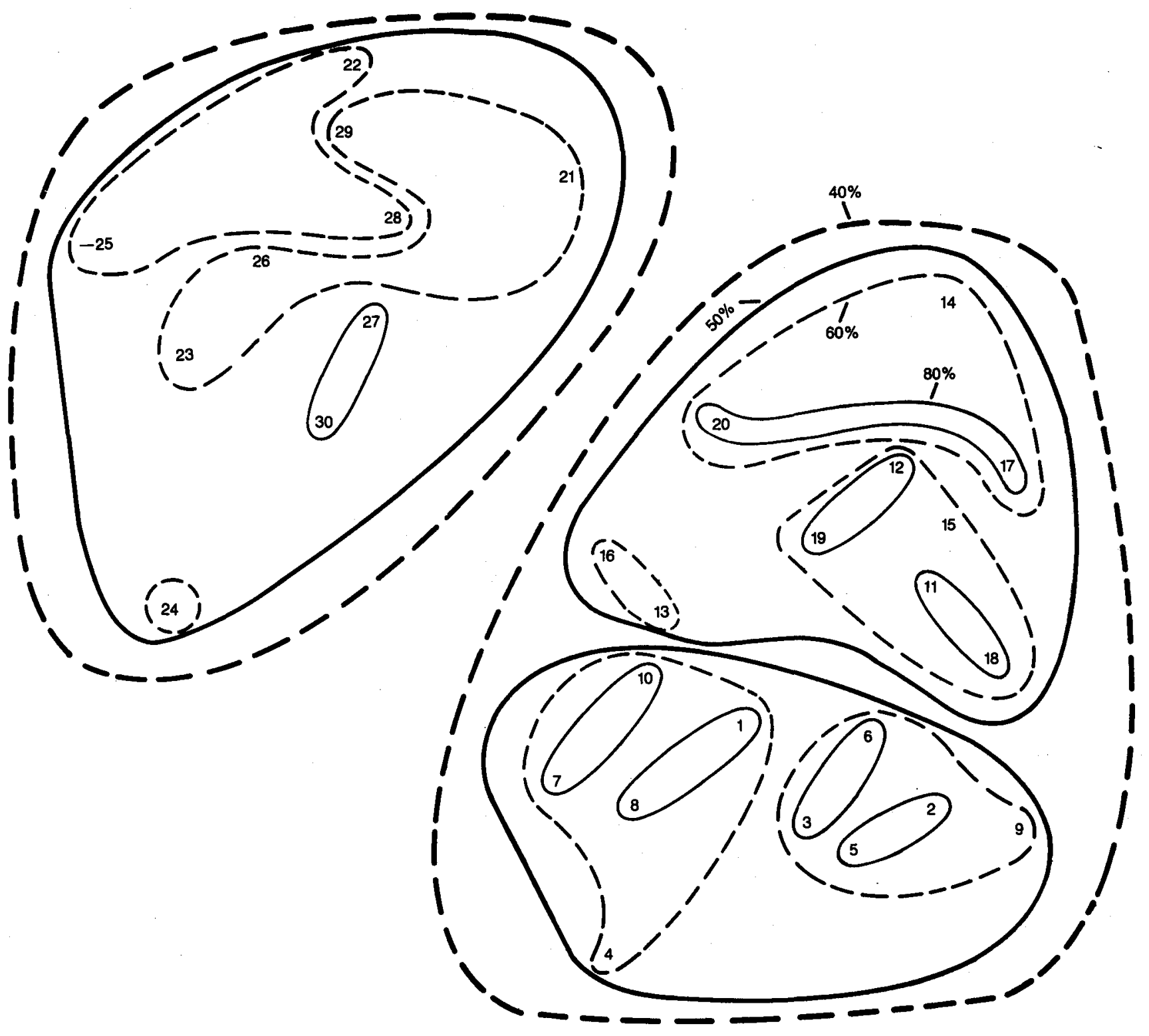


14. Schulten, H.-R., N. Simmleit and H. H. Rump: Soft ionization mass spectrometry of epicuticular waxes isolated from coniferous needles; Chem. Phys. Lipids, in press.

15. Klus, $H$., and $H$. Kuhn: Verteilung verschiedener Tabakrauchbestandteile auf Haupt- und Nebenstromrauch (Eine Übersicht); Beitr. Tabakforsch. Int. 11 (1982) 229-265.

16. Chortyk, O. T., and W. S. Schlotzhauer: Studies on the pyrogenesis of tobacco smoke constituents (a review); Beitr. Tabakforsch. 7 (1973) 165-178.

17. Simmleit, N., and H.-R. Schulten: Differentiation of commercial tobacco blends by pyrolysis field ionization mass spectrometry and pattern recognition; Fresenius Z. Anal. Chem. 324 (1986) 9-12.
Acknowledgements

This work was supported financially by the Deutsche Forscbungsgemeinschaft (research projects $S c h u$ 416/6-1 and 416/8-1) and the Bundesministerium für Forschung und Technologie (research project 037383 6), Bonn-Bad Godesberg, Federal Republic of Germany.

Autbor's address:

Department of Trace Analysis, Fachbochschule Fresenius,

Dambachial 20,

D-6200 Wiesbaden,

Federal Republic of Germany. 